\title{
Journal of Linguistics
}

http://journals.cambridge.org/LIN

Additional services for Journal of Linguistics:

Email alerts: Click here

Subscriptions: Click here

Commercial reprints: Click here

Terms of use : Click here

\section{Janet Dean Fodor: Semantics: theories of meaning in generative grammar. New York: Crowell, 1977. Pp. xi +225.}

Deirdre Wilson

Journal of Linguistics / Volume 14 / Issue 01 / March 1978, pp 115 - 118

DOI: 10.1017/S0022226700005752, Published online: 28 November 2008

Link to this article: http://journals.cambridge.org/

abstract_S0022226700005752

How to cite this article:

Deirdre Wilson (1978). Review of Janet Dean Fodor 'Semantics: theories of meaning in generative grammar' Journal of Linguistics, 14, pp 115-118 doi:10.1017/S0022226700005752

Request Permissions : $\underline{\text { Click here }}$ 
Janet Dean Fodor: Semantics: theories of meaning in generative grammar. New York: Crowell, 1977. Pp. xi +225.

One can reasonably expect a textbook to be comprehensive, objective and critical, and Janet Fodor's book is all of these. What is particularly impressive about it, however, is that it manages to combine these basic qualities with the less predictable ones of originality and excitement. The result is a very good book indeed.

According to the preface, Fodor's aim in writing the book was to provide a review of the competing theories and conclusions that have been put forward since work on semantics within generative grammar began some fifteen years ago. The intention was not to argue for one particular theory over others, but merely to give a fair hearing to each, keeping to 'a rough principle of equal, and equally critical, representation'. The main theories considered are the standard-theory approach of Katz (1972), the generative semantics approach, and the extended standard-theory approach of Jackendoff (1972); other theories less extensively discussed are those of Fillmore (1968), Gruber (1965), Montague (1974), Davidson (1967), and Chomsky (1975). Fodor fulfils her stated aims at a very high level: her presentation is clear, her summaries are fair, and her criticisms invariably sound and unpolemical. Interleaved with this are a series of subtle and original reflections on the nature of meaning, semantic theory and semantic description, which go far beyond what one would normally expect to find in a textbook, and which give the book its original and exciting qualities. Rather than attempting a chapter-by-chapter summary, I want to take up two or three strands of argument from different parts of the book, which Fodor never explicitly pulls together, but which seem to me, when combined, to justify a quite substantial departure from our current conceptions of semantics.

The explication of meaning and meaning-related notions such as synonymy, ambiguity, analyticity, etc., has never been a central concern of generative linguists. In Chapter II, Fodor discusses the extensive philosophical literature on this topic, and shows that virtually every theory of meaning so far put forward is defective in one of two ways. Either it succeeds in defining meaning, synonymy, etc., but in such a way that it makes false predictions about which sentences actually are meaningful, synonymous, etc; or it is viciously circular, in that it succeeds in defining one of these interrelated terms only by presupposing an intuitive understanding of another. Referential, ideational and behavioural theories generally fall into the first class; theories of meaning as analytic entailment or illocutionary force generally fall into the second. Certain rather sophisticated theories, for example Davidson's (1967) version of truth-conditional semantics and some versions of possible-world semantics, manage to fall into both classes at once.

Consider, for example, a theory which claims that meaning is definable in 
terms of necessary truth-conditions. Such a theory will falsely predict that sentences which share their truth-conditions must be synonymous, and hence that all logically equivalent sentences must mean the same. Instead of concluding that truth-conditional semantics is thereby refuted, Fodor tentatively endorses Carnap's (1947) solution to the problem, arguing that an adequate theory of meaning must incorporate something like Carnap's notion of intensional isomorphism if it is to be capable of making correct synonymy judgments. The relevant feature of Carnap's approach is that he allows two sentences to count as non-synonymous, even if they share their truth-conditions, as long as they differ in the routes by which these truth-conditions are constructed. In more familiar terms, he allows two sentences which share their semantic representations to count as nonsynonymous as long as the mechanisms by which these semantic representations are assigned differ from one sentence to the other.

I do not think that this proposal goes nearly far enough towards solving the problem. There is something profoundly unsatisfactory about claiming that two sentences which share their semantic representations may none the less differ in meaning, as long as they differ in the manner by which these semantic representations are constructed. What is needed is an approach which allows differences in the way in which a semantic representation is constructed to be reflected by differences in the semantic representation itself. In other words, one needs to know not just THAT differences in manner of construction may render two semantic representations non-equivalent, but also WHAT differences in meaning they actually make. I shall have some suggestions to make about this later.

In Chapter V, Fodor discusses the nature of semantic representations as traditionally conceived. Are they really necessary? She shows that there is at least a reasonable alternative to a semantic component which associates a single semantic representation with each unambiguous sentence: 'A grammar without semantic representations, but with a suitable body of inference rules, could apparently do everything that has traditionally been demanded - as long as it is the case that all the significant semantic properties and relations of a sentence can be captured by reference to its entailments' (194). The idea behind this proposed shift in approach is that the semantic rules, conceived of as inference rules, need not necessarily integrate all the semantic information carried by a sentence into a single hierarchical structure which completely exhausts the meaning of the original sentence: indeed, there are certain cases where they not only need not but cannot. A desire for homogeneity would argue that because some semantic rules cannot be conceived of as translation rules, none should; hence semantic rules should be seen as inference rules which yield an unintegrated, unstructured series of entailments. Fodor remarks that it is unclear what implications this view of semantic interpretation has for the characterization of intensional isomorphism and, through it, for the definition of synonymy 
and other meaning-related notions. Without some reconstruction of intensional isomorphism Fodor's proposed theory is clearly going to make the false prediction mentioned earlier, that all sentences which share their entailments must be synonymous.

It seems to me that the answer to this problem is identical with the answer to another problem which Fodor makes no attempt to solve: what is it that accounts for the well-known phenomenon of presuppositional behaviour? Fodor frequently alludes to this, without giving it the critical attention she devotes to other topics of more central interest to her. However, she appears to endorse the view that there must be some semantic property which would correlate with pragmatic differences between propositions which are explicitly asserted and those which are taken for granted. Again, though I do not believe that the presupposition-entailment distinction is adequate for this purpose, I would like to support Fodor's claim that there must be something in the semantic structure of a sentence which may be used to predict the differences in behaviour of its constituent propositions on the pragmatic level.

It is clear, then, what requirements Fodor would like to place on an adequate semantic theory. It must characterize the meaning of a sentence in terms of its entailments. However, it must be able to distinguish between sentences which have exactly the same set of entailments, but which are non-synonymous; and it must also be able to distinguish among different CLASSES of entailment, so that various aspects of presuppositional behaviour may be accounted for. It seems rather obvious that one can satisfy these requirements simultaneously, thus reducing the problem of presuppositions and the problem of intensional isomorphism to one and the same thing.

Suppose that one took the meaning of a sentence to be, not an unstructed set of entailments, as Fodor does, but an organized, partially ordered set. The semantic ordering could be pragmatically interpreted as imposing an order of importance on the various propositions entailed by the sentence, thus accounting for their differing pragmatic potentialities under assertion, questioning and denial, and hence solving the presupposition problem. Interestingly, it would simultaneously provide for the possibility that sentences which shared their entailments but ordered them differently should count as non-synonymous, thus solving the problem of intensional isomorphism by allowing differences in manner of construction to be reflected in differences in output of the semantic rules. Recent work by Wilson and Sperber (to appear) suggests that an approach along these lines is perfectly feasible. It essentially makes use of the syntactic, lexical and phonological structure of a sentence to impose a partial ordering on its entailments; this partial ordering is then used to make predictions about pragmatic uses and semantic relations of the sentence with which it is associated. The empirical claim being made is that differences in presuppositional structure will correlate with differences in meaning, and that the semantic structure needed 
to predict pragmatic presuppositional behaviour is precisely the same as the structure needed to reconstruct Carnap's notion of intensional isomorphism. While Fodor does not herself make this connexion, the arguments she has given point naturally towards it, and hence towards a rather radical revision in our current views of semantics. All this is done quite incidentally to her stated central aim of reviewing the standard generative literature; the book is therefore rewarding on two quite different levels.

The Language and thought series, of which this book forms a part, has now produced two items of compulsory reading for anyone with an interest in semantics: the present volume, and Jerry Fodor's The language of thought (1975), in my opinion one of the best books published in the last ten years. The prices of this series are prohibitive: there is a clear need for a paperback edition, so that these books can have the readership they deserve.

\section{REFERENCES}

Carnap, R. (1947). Meaning and necessity. University of Chicago Press.

Chomsky, N. (1975). Reflections on laniguage. New York: Pantheon Books.

Davidson, D. (1967). Truth and meaning. Synthese 17. 304-323.

Fillmore, C. (1968). The case for case. In Bach, E. \& Harms, R. T. (eds) Universals in linguistic theory. New York: Holt, Rinehart \& Winston.

Fodor, J. A. (1975). The language of thought. New York: Crowell.

Gruber, J. (1965). Studies in lexical relations. Ph.D. thesis, M.I.T.

Jackendoff, R. (1972). Semantic interpretation in generative grammar. Cambridge, Mass.: M.I.T. Press.

Katz, J. (1972). Semantic theory. New York: Harper Row.

Montague, R. (1974). Formal philosophy: selected papers of Richard Montagute. In R. Thomason (ed.) New Haven, Conn.: Yale University Press.

Wilson, D. \& Sperber, D. (to appear). Ordered entailments: an alternative to presuppositional theories. In Oh, C. K. (ed.), Syntax and semantics: presuppositions. New York: Academic Press.

(Received 30 July 1977)

Reviewed by DeIRDRE WILSON, Department of Linguistics, University College London.

Thomas A. Sebeok (ed.), Current trends in linguistics, Vol. 13: Historiography of linguistics. The Hague: Mouton, 1975 [1977]. Pp. xviii +716, 717-1518.

With these two tomes a huge, expensive and ill-disciplined project is effectively completed. Only an index volume (volume, one hopes, not volumes) is to come. It is typical of the editor's method that a subject to which he had originally allotted one chapter in Vol. 12 (ii) should take up over twice the space of Vol. 3 (Theoretical foundations), with which publication began.

The content of the volume is divided into three unequal parts. Part $3(\mathrm{I} 38 \mathrm{I}-$ I 446 ) is a 'Bibliography of the history of linguistics' by E. Stankiewicz, divided 